ppi $201502 Z U 4645$

Esta publicación científica en formato digital es continuidad de la revista impresa ISSN-Versión Impresa 0798-1406 / ISSN-Versión on line 2542-3185Depósito legal pp $197402 Z$ U34

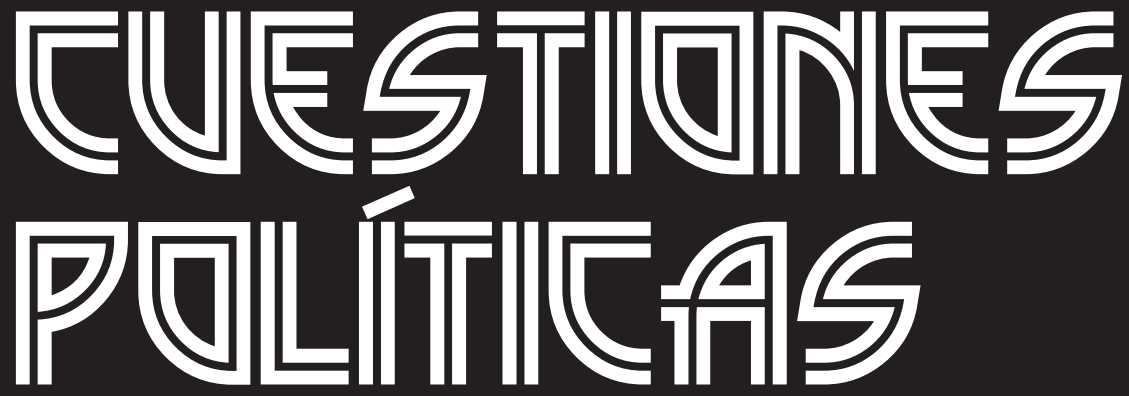

Instituto de Estudios Políticos y Derecho Público "Dr. Humberto J. La Roche" de la Facultad de Ciencias Jurídicas y Políticas de la Universidad del Zulia Maracaibo, Venezuela
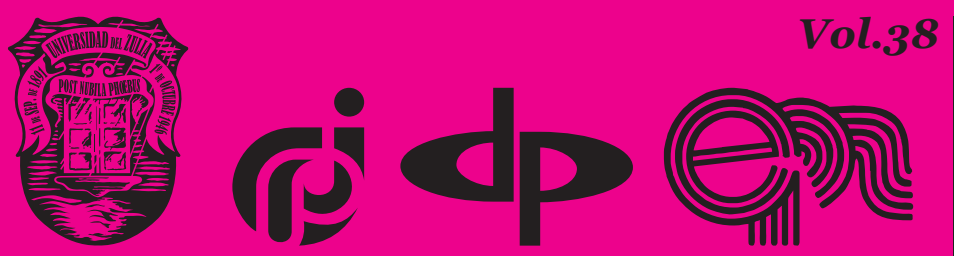

$N^{\circ}$ Especial 1era Parte 2020 


\title{
Lecturas del miedo y control social en la teoría sociocrítica y posmoderna
}

\author{
DOI: https://doi.org/10.46398/cuestpol.38e.o1
}

\author{
Panchenko Olha * \\ Danilyan Oleg $\mathbf{G}$. ** \\ Viktoriia Lytuyn *** \\ Diego Felipe Arbeláez-Campillo **** \\ Magda Julissa Rojas-Bahamón **** \\ Maryna Halych \\ Larysa Ryby $k$ *******
}

\section{Resumen}

Históricamente el factor miedo a las amenazas ha desempeñado un rol fundamental en la legitimación de los sistemas políticos y sociales porque se presentan como la encarnación de un poder para la protección de personas y comunidades ante los distintos peligros que afectan a una sociedad determinada, de ahí que el miedo además se constituye en una fuerza que propicia en cada momento el despliego de los dispositivos del control social, formales e informales para disciplinar y castigar de ser preciso. El objetivo de este artículo científico radica en debatir distintas lecturas sobre el binomio: miedo y control social en los dominós del derecho, la teoría crítica de la sociedad, el pensamiento postestructuralista de Michel Foucault y la doctrina del shock. La investigación transcurrió en las coordenadas de la hermenéutica y la metódica de las entrevistas abiertas con guion semiestructurado como excusa para triangular los postulados de las teorías seleccionadas, la opinión de dos expertos en la materia y la perspectiva particular del equipo de investigación. Entre los hallazgos concluyentes de

* PhD in Law, Specialist of the Department of Doctorate and Post-graduate Studies of the National Academy of Internal Affairs. ORCID ID: https://orcid.org/oooo-00o3-4365-0495. Email: olia. pan4encko@ukr.net

** Doctor of Philosophical Sciences, Professor, Head of the Department of Philosophy of Yaroslav Mudryi National Law University. ORCID ID: https://orcid.org/oooo-ooo1-5308-4664. Email: odana@i.ua

*** PhD in Law, Lecturer of the Department of Legal Psychology of the National Academy of Internal Affairs. ORCID ID: https://orcid.org/oooo-0002-2029-0346. Email: post@naiau.kiev.ua

**** Grupo de investigación Lenguajes, representaciones y Educación, Universidad de la Amazonia (Colciencias- Colombia). ORCID ID: https://orcid.org/oooo-0002-9041-9563. Email: dfaca@hotmail. com

***** PhD. Educación y cultura ambiental. Docente IE Jorge Eliecer Gaitán, Universidad de la Amazonia, Colombia. ORCID ID: https://orcid.org/oooo-0003-4882-1476. Email: mjulissa@gmail.com

****** Lecturer of the Department of Legal Psychology of the National Academy of Internal Affairs. ORCID ID: https://orcid.org/oooo-0o02-3690-4402. Email: post@naiau.kiev.ua

******* Candidate of Psychological Science, Psychologist of the National Center for Severe Losses. ORCID ID: https://orcid.org/oooo-0002-3280-1406. Email: post@naiau.kiev.ua 
Panchenko. Olha, Danilyan, Oleg G., Viktorïa Lytuyn, Diego Felipe Arbeláez-Campillo, Magda Julissa Rojas-Bahamón, Maryna Halych y Larysa Rybyk

Lecturas del miedo y control social en la teoría sociocrítica y posmoderna

la investigación destacan que en cualquier escenario venidero las estrategias de resistencia civil y movilización ciudadana juegan un rol primordial para inclinar la balanza del lado de las democracias.

Palabras clave: teoría sociocrítica; imaginarios colectivos del miedo; control social; sistemas de dominación; pensamiento contrahegemónico.

\title{
Readings of Fear and social control in sociocritical and postmodern theory
}

\begin{abstract}
Historically, the fear of threats factor has played a fundamental role in the legitimization of political and social systems because they are presented as the embodiment of a power for the protection of people and communities against the different dangers that affect a given society, hence that fear constitutes a force that fosters at all times the deployment of formal and informal social control devices to discipline and punish if necessary. The objective of this scientific article is to debate different readings on the binomial: fear and social control in the dominoes of law, the critical theory of society, and the post-structuralist thought of Michel Foucault and the doctrine of shock. The research was carried out in the coordinates of hermeneutics and the method of open interviews with a semi-structured script as an excuse to triangulate the postulates of the selected theories, the opinion of two experts in the field and the particular perspective of the research team. Among the conclusive findings of the research, it is highlighted that in any future scenario the strategies of civil resistance and citizen mobilization play a fundamental role to tip the balance on the side of democracies.
\end{abstract}

Keywords: socio-critical theory; collective imaginary of fear; social control; domination systems; counter-hegemonic thinking.

\section{Introducción}

Desde el surgimiento de los sistemas políticos complejos en ciertas sociedades humanas dela antigüedad como: Sumeria, China, el valle del Indo y Egipto se visualiza la estructuración de un proto-estado que implementa sistemáticamente un conjunto de tecnologías para la dominación y el control 
social -en adelante solo CS- como condición de posibilidad para mantener en el tiempo el statu quo. En efecto, el CS responde a la necesidad del poder instituido de garantizar que las personas en sus interacciones sociales no trasgredan la concepción de normalidad ${ }^{8}$ con base a los parámetros morales que define un tiempo y espacio particular y racionaliza el derecho. Sin lugar a duda, la modernidad del occidente hegemónico ha llevado el CS a horizontes sorprendentes que evocan a ficciones distopías9.

$\mathrm{Al}$ decir de CRIMINA (2014), la noción de CS devela las distintas formas y métodos mediante los cuales el Estado intenta impedir y castigar las llamadas "conductas desviadas" que transgreden lo moralmente aceptable y al mismo tiempo son acreedoras de castigos (sanciones penales), por lo demás: "Diversos métodos se han empleado en las distintas sociedades a través del paso del tiempo con el objetivo de tratar de asegurar la convivencia pacífica o de imponer castigos a aquellos que quebrantaran las normas sociales" (CRIMINA, 2014: 02). No es la intención de esta investigación dar cuenta de las distintas teorías criminológicas sobre el CS y sus variados epifenómenos.

La relación entre derecho y CS es consustancial porque, por un lado, el derecho positivo, esto es, el compilado en los distintos códigos, reglamentos, leyes, edictos y cuerpos normativos en general para estricto acatamiento de las personas y autoridades en sus mundo de vida, encarga en buena medida los saberes propios de la tradición y del derecho consuetudinario para determinar lo aceptado o reprochable en una comunidad y; por el otro, el CS sirve especialmente de fuerza legitimadora a los interés de los grupos de poder que vigilan y castigan -de ser necesario- para impedir todo intento individual y colectivo de subvertir el orden societal y, más aún, de implementar uno distinto. Por estas razones y por otras, el CS produce y reproduce el miedo al castigo como una suerte de muro simbólico de contención a la puesta en marcha de prácticas disruptivas para la paz y la estabilidad del sistema.

8 Los trabajos del psiquiatra cercano a los postulados de la Escuela de Frankfurt, Erich Fromm, demuestran que en la sociedad moderna el concepto de normalidad es cuanto menos paradójico y polémico. Se trata de un invento de la psicología clínica para tipificar como patológicas a todas las conductas que no respondan a los requerimientos productivos de la economía capitalista, para la cual solo importa la dimensión económica del hombre en su afán permanente de consumo. Por lo demás, para Fromm (1994; 2003), la idea de normalidad que subyace en la racionalidad instrumental de las sociedades abiertas es patológica por sí misma, porque, entre otras cosas, cuarta toda posibilidad de pensar críticamente. Esta visión no niega la existencia de los trastornos mentales, solo intenta exponer el uso político e ideológico de la psicología clínica y la psiquiatría en tanto herramienta de control social.

9 En este punto pensamos por ejemplo en la novela de la autoría de George Orwell intitulada 1984, que describe una sociedad totalitaria dominada por una autoridad omnipotente llamada Gran hermano que no solo controla a la sociedad, sino incluso el uso del lenguaje y los pensamientos y sentimientos más íntimos de las personas comunes. A la final, la novela termina describiendo como este sistema, con sus múltiples y sofisticados mecanismos de control social, termina literalmente por quebrar al personaje principal en su tímido afán de rebeldía y en su intento por desarrollar un proyecto de vida en un umbral mínimo de libertad para ser y hacer. 
Panchenko Olha, Danilyan, Oleg G., Viktoriia Lytoyn, Diego Felipe Arbeláez-Campillo, Magda Julissa Rojas-Bahamón, Maryna Halych y Larysa Rybyk

Lecturas del miedo y control social en la teoría sociocrítica y posmoderna

El CS es, por tanto, un fenómeno propio de todas las formaciones sociales a través de la historia, necesario para la gestión del conflicto social que se origina en el reparto desigual de los bienes de valores (Villasmil, 2017) y, de contera, para el mantenimiento de los distintos espacios de convivencia más allá de los conflictos, tensiones y contradicciones que emergen de las relaciones intersubjetivas entre personas, grupos e instituciones. En este sentido, el CS ha suscitado lógicamente el desarrollo de un conjunto de escuelas y teorías que intentan explicar a su modo, desde la perspectiva de disciplinas como: el derecho, la sociología o la criminología; su origen, tecnologías y resultados.

El objetivo de este artículo científico radica en debatir distintas lecturas sobre la dialéctica: miedo y CS en los dominós del derecho, la teoría crítica de la sociedad, el pensamiento postestructuralista de Michel Foucault y la doctrina del shock, por ser a nuestro entender los desarrollos contemporáneos que más aportes han efectuado a la comprensión de este fenómeno relacional en clave crítica y contrahegemónica.

Se considera que el objetivo está ampliamente justificado en la realidad pasada y presente que posiciona a los imaginarios colectivos del miedo, como un agente esencial en la legitimación del CS bajo la hipótesis que este sostiene -como una columna vertebral- a los sistemas políticos y sociales que se presentan como la encarnación de un poder vinculante para la protección de personas y comunidades por ante los distintos peligros que afectan su devenir. De ahí que el miedo se constituye además en una fuerza formidable que propicia en cada momento el despliego de los dispositivos del CS, -formales e informales- para disciplinar y castigar personas y colectividades de ser preciso. Esta hipótesis no niega que además del miedo, el CS se justifique en otros factores materiales o simbólicos.

Eltrabajosedivideen cuatroseccionesparticularesperointerrelacionadas en su propósito de responder al objetivo de la indagación. El primer punto Problema y marco teórico, ilustra sobre el contenido y significación de la literatura científica seleccionada para estructurar el aparato analítico y crítico que sirvió de modelo interpretativo de los fenómenos en debate. En el segundo apartado se explica el proceso metodológico que avaló los resultados obtenidos. En el tercer punto Miedo y control social en la teoría sociocrítica y posmoderna, se intentó contribuir -al menos parcialmentecon la resolución del objetivo, al tiempo que se sintetizan los principales hallazgos obtenidos en las entrevistas a dos destacados científicos sociales; por el último, se arriba a las principales conclusiones como un intento de promover un debate académico sobre el miedo/ CS en el convulso mundo de hoy signado por los estragos ocasionados por el COVID-19. 


\section{Problema y marco teórico}

Las teorías críticas que intentan exponer científicamente los abusos y contradicciones autoritarias de los poderes hegemónicos para la dominación social, en beneficio de elites económicas y sociopolíticas que asuman el CS -formal e informal- en su propio beneficio, bien sea para garantizar de forma sostenida el goce y disfrute de un conjunto de privilegios particulares en detrimento de las grandes mayorías o, para imponer una concepción del poder y del orden social que justifica las formas de violencia, explotación y exclusión sobre personas, grupos y comunidades que revindican identidades y prácticas que cuestionan, de algún modo, la noción de normalidad de forma de legitima, no niegan a priori la utilidad del CS, con la excepción de los anarquistas.

Por regla general, de lo que se trata en el pensamiento sociocrítico y posmoderno es de explicar, con base a evidencia empírica concreta, las tecnologías de CS que se usan para apuntalar históricamente ordenamientos que en la dimensión política, económica y social menoscaban la dignidad humana y sirven de óbice al desarrollo de una vida de calidad que, como sostienen Nussbaum (2012), valga la pena ser vivida. En este hilo conductor el problema se formula en las preguntas: ¿todos los sistemas conocidos de CS precisan como condición de posibilidad de los imaginarios sociales del miedo? ¿Ciertas coyunturas catastróficas como las pandemias auspician el uso arbitrario del CS a través de la inducción colectiva del miedo? Estas y otros preguntas similares se efectuaron a dos investigadores sociales de reconocida solvencia.

Cuando se habla de CS formal, no referimos a las normas, discursos y prácticas que son avaladas y socializadas ${ }^{10}$ en todo momento por un conjunto de instituciones sociales (instituciones de poder) como: la escuela, la religión, la familia, las universidades, los órganos del estado, los medios de comunicación y especialmente por el derecho, entre otras, para regular por igual la conducta de las personas concretas en sus interacciones cotidianas. En consecuencia, es el derecho penal la principal disciplina garante del mantenimiento y conservación del orden social, desde la cual se identifican y castigan los ethos que erosionan al "interés general", al tiempo que se edifican las narrativas sobre lo admisible y lo inadmisible, lo valido y lo invalido y sobre lo ético o reprochable para una sociedad (Foucault, 2008).

Por su parte, el CS informal es quizá más difícil delimitar porque se manifiesta en los espacios simbólicos de una cultura particular y, por su naturaleza dinámica e intangible, es susceptible preferiblemente

10 Para un estudio pormenorizado de los procesos de socialización política en general se recomienda consultar el trabajo de MORALES CASTRO, Yolanda Rosa. 2018. Familia y socialización política en Colombia. UNERBM/Universidad del Zulia. Cabimas, Venezuela. 
Panchenko Olha, Danilyan, Oleg G., Viktoriia Lytoyn, Diego Felipe Arbeláez-Campillo, Magda Julissa Rojas-Bahamón, Maryna Halych y Larysa Rybyk

Lecturas del miedo y control social en la teoría sociocrítica y posmoderna

a investigaciones cualitativas pen el marco de la hermenéutico y la fenomenología, para las cuales las escalas de cuantificación no son suficientes cuando se trata de reconstruir fenómenos subjetivos en los que se entrelazan dialécticamente procesos individuales y colectivos, materiales y culturales, afectivos y cognitivos. A veces se da una completa sintonía entre el CS formal e informal, en otros casos, las instituciones objetivas del poder vinculante adquieran parámetros legales que provienen de otras latitudes diferentes y no responden a los saberes y rituales del derecho consuetudinario y la tradición. De cualquier modo, como admite David (1979), los límites que hay entre los sistemas formales e informales de control son tenues y difusos:

(...) yo he mencionado muchas veces... las contradicciones que hay entre la estructura formalista, universalista, de la Ciencia del Derecho y de los Códigos; y al mismo tiempo, las presiones particulares del poder, amistad, economía, etc., que se dan en la realidad social. De forma tal, que contra un sistema formal tenemos un sistema informal; y ese sistema informal muchas veces contrala y dirige al sistema formal (1979: 33).

La complejidad de las realidades sociales gestadas históricamente rebasa las posibilidades heurísticas y hermenéuticas de las distintas teorías y disciplinas que se esfuerzan en estudiar parcialmente las dinámicas de CS. Esta situación verdaderamente impone una agenda de investigación holísticas e interdisciplinaria, que conjugue o confronte en igualdad de condiciones diferentes enfoques, métodos y perspectivas de análisis.

En el caso latinoamericano, verbigracia, la disonancia entre los modelos institucionales típicos de la modernidad (Márquez Ramírez, 2020) y las realidades socioculturales de los colectivos de esta región ha sido dramática, porque aún hoy discursos políticamente correctos como: derechos humanos, democracia, desarrollo económico o participación ciudadano, no han echado raíces suficientes en la cultura popular ni, muchos menos, en los imaginarios de las elites de poder que siguen ancladas, segundo la relectura de Max Weber de Canelón (2009), a la dominación carismática que propicia el caudillismo y la personalización radical de la política en detrimento del orden legal-racional.

La teoría crítica de la sociedad confeccionada por la primera y segunda generación de la célebre escuela de Frankfurt manifestó un interés central en los mecanismos informales de CS, característicos de las sociedades contemporáneas, modeladas por el eje transversal del consumismo y la democracia representativa de raigambre liberal. En este escenario, obras como: (Horkheimer y Adorno, 1998; Marcuse, 1993; Fromm, 1994; 2003; Habermas, 2000; 1999; Benjamin, 2001) exponen que más allá de la impronta del positivismo y la racionalidad iluminista del siglo de las luces, las libertades individuales son obliteradas en occidente, no solo por los regímenes fascistas y comunistas contrarios a la democracias, sino 
que en las mismas "democracias liberales", se despliegan un conjunto de sutiles mecanismos que instrumentalizan la condición humana, dificultan la autodeterminación del ser e impiden, por lo tanto, el ejercicio de la soberanía individual.

\section{Figura No. 1. Representación concéntrica de las teorías seleccionadas en el estudio (Elaboración propia con base al objetivo de la investigación).}

Según Laso (2004), el aporte de la teoría crítica de la sociedad radica en desarrollar precisamente el carácter desmitificador de las ciencias sociales en un mundo que se encuentra en permanente riesgo de autodestrucción como resultado de avances tecnológicos que más que ser medios al servicio del desarrollo humano, se posicionan ahora como fines en sí mismos, para apalancar mecánicas de dominación y explotación de personas y naciones enteras.

En consecuencia, la escuela de Frankfurt construyó una epistemología, inter y trans-disciplinaria con base en el psicoanálisis y al marxismo revisionista para denunciar las contradicciones de los modelos políticos, económicos y sociales que emergen de la modernidad y, de igual modo, exponer el papel de las ideologías, el miedo al cambio y el CS principalmente en las "sociedades avanzadas" de la de cada de los sesentas y setentas, apostando por el despertar del pensamiento crítico y asociativo como herramienta de cambio político de cara a la democracia deliberativa y a la democracia de base que dota de protagonismo a la ciudadanía en la construcción de sus propios espacios de convivencia, prescindiendo incluso de la burocracia y el gobierno. 
Panchenko Olha, Danilyan, Oleg G., Viktoriia Lytoyn, Diego Felipe Arbeláez-Campillo, Magda Julissa Rojas-Bahamón, Maryna Halych y Larysa Rybyk

Lecturas del miedo y control social en la teoría sociocrítica y posmoderna

En la misma línea revisionista y contrahegemónica, en la segunda mitad del siglo XX el pensamiento postestructuralista de Michel Foucault propone nuevas miradas inclusivas, para repensar el rol en la sociedad moderna de grupos marginados como: los homosexuales, los prisioneros o los orates -señalados como promotores primarios de conductas desviadas-, desde constructos epistemológicos que dan al traste con la racionalidad positivista. En cierto modo, Foucault es sin proponérselo el primer pensador posmoderno ${ }^{11}$ que cuestiona la confianza de la modernidad en una supuesta racionalidad universal capaz de impulsar indefinidamente el avance de las sociedades o, del mesianismo del sujeto proletario para impulsar "revoluciones exitosas" al estilo marxista, devenidas en el socialismo real en totalitarismos.

El filósofo francés formula en sus ensayos (Foucault, 1980; 2002; 2008; ) una analítica distinta del poder social, según la cual este no es un recurso o atributo que pueden poseer las elites posicionadas en el vértice de la pirámide social, tal como pensaron marxistas y estructuralistas; sino más bien, un fenómeno relacional simultáneamente simbólico y material que se manifiesta en cada momento por el resultado de una red multivariada en la que confluyen saberes, personas e instituciones de todo tipo desde la base del orden social para desplazarse en todas direcciones.

De hecho, para Foucault los sistemas de dominación y CS, se dan originalmente en el seno de relaciones interpersonales que denominó como microfísica del poder. Piénsese, por ejemplo, en un profesor autoritario en el panóptico de un aula de clase, o un hombre machista cuartando las posibilidades de desarrollo de su esposa o, en un empresario xenófobo que contrata migrantes ilegales en el norte global para explotarlos al máximo. Son estas pequeñas dominaciones cotidianas normalizadas o invisibilizadas por la cultura dominante, las que propician las condiciones de posibilidad de la gran dominación sistémica y las que legitiman el CS con base al miedo (Foucault, 2007).

En cuanto al miedo conviene destacar que en muchos casos se presenta como un factor inhibidor de la acción colectiva, retardando los necesarios procesos de cambio que rompen con el estancamiento de la tradición e impulsan -bajo ciertas condiciones- el salto cuántico de la humanidad a una fase cualitativamente superior de su existencia o, al menos, propician acciones de resistencia y protesta social. En este sentido, Hurtado (2015) sostiene que el miedo es un universal cultural y que tiene su manifestación máxima en el temor a la muerte:

11 El pensamiento de Foucault es posmoderno al decir de Canelón (2009), porque cuestiona la racionalidad instrumental y la primacía de la ciencia como operadora de la acción humana y social. Además, reivindica abiertamente las identidades y estilos de vida alternativos que se contraponen a las culturas dominantes. Se trata, en síntesis, de una denuncia a los grandes metarrelatos y a la visión evolutiva y lineal de la historia propiciada por liberales y positivistas por igual y, fundamentalmente, de una invitación al reconocimiento por parte de las ciencias sociales y humanas de nuevos o renovados actores sociales y sujetos políticos subordinados por la modernidad como proyecto de investigacion. 


\begin{abstract}
El miedo a la muerte ha acompañado a nuestra especie desde sus orígenes y se encarna en cada uno de nosotros. Como expone Bauman: "el miedo original es el miedo a la muerte, es un temor innato y endémico que todos los seres humanos compartimos, por lo que parece, con el resto de animales, debido al instinto de supervivencia programado en el transcurso de la evolución en todas las especies animales" (2007: 46). Además de este miedo, podemos rastrear desde las primeras expresiones culturales que nos han dejado nuestros antepasados, la presencia del miedo a las fuerzas de la naturaleza, a lo sobrenatural, al otro, al diferente (2015: 267) (negritas añadidas).
\end{abstract}

Visto así, el miedo es una emoción consustanciada al ser humano desde sus orígenes remotos, que surge normalmente como reacción a fuerzas y situaciones desconocidas que pueden amenazar la vida y tranquilidad de personas y grupos por igual. De este modo, el manejo político del imaginario colectivo del miedo es una variable que entra en los cálculos de todos los gobiernos en general y de los de tipo autoritario en particular.

$\mathrm{Al}$ decir de Salazar (2015), en el mundo globalizado de hoy, los Mass media han distorsionado su rol informativo para convertirse ahora en una pieza central dentro del engranaje del ejercicio del poder, perturbando las subjetividades colectivas mediante una agenda que genera angustia y zozobra en la población en general. Esta realidad explica el interés creciente de los gobiernos y grupos de poder por controlar y regular no solo la prensa en general, sino, además, las redes sociales y el internet.

En este contexto de erosión comunicacional por parte del discurso hegemónico, los medios se constituyen según Salazar (2015), en el nuevo dispositivo informal de CS, remplazando de cierto modo las tradicionales prácticas represivas de las fuerzas del orden público por efecto de la represión ideológica que, en particulares escenarios de arbitrariedad, crisis y medio -agregamos nosotros como la sucedida en la actualidad por el efecto devastador del nuevo coronavirus-, propician la represión ideológica y el deterioro del pensamiento crítico mediante una estrategia de guerra informativa de baja intensidad, que moldea la opinión pública para aceptar o rechazar ciertas matrices o temas de interés, en el marco de un miedo constante y latente que solo beneficia al poder constituido.

Ya en el siglo XXI la connotada obra de Klein (2008) La doctrina del shock El auge del capitalismo del desastre es la que mejor sintetiza los postulados del pensamiento sociocrítico y posmoderno. Básicamente se describen aquí los distintos mecanismos a través de los cuales los gobiernos manejan las crisis o, inclusive, las propician o crean deliberadamente para generar las condiciones suficientes y necesarias que permitan adelantar decisiones impopulares a contravía del verdadero interés general de las sociedades. La doctrina del shock expone racionalmente los vericuetos de un experimento social en el que participan el gobierno al más alto nivel y 
Panchenko Olha, Danilyan, Oleg G., Viktoriia Lytvyn, Diego Felipe Arbeláez-Campillo, Magda Julissa Rojas-Bahamón, Maryna Halych y Larysa Rybyk

Lecturas del miedo y control social en la teoría sociocrítica y posmoderna

distintos grupos de poder en alianza con los mass media, para controlar las representaciones sociales de una crisis y, primordialmente, legitimar políticas neoliberales que profundizan en muchos sentidos la injusticia, la arbitrariedad y la subordinación de grupos y minorías en condición de emergencia social.

No obstante, esta doctrina que busca distraer a los espectadores desprevenidos de las temáticas centrales en los dominios de la realidad social y mediática en las que están inmersos, para anular su repertorio crítico mediante la inducción de un estado de shock o conmoción general, en el cual se terminan por confundir problemas y soluciones, causas y efectos en términos de políticas públicas, responsables y víctimas, no solo es de utilidad para imponer un conjunto de medidas económicas, sino también, todo tipo de planes y proyectos hegemónicos que confunden a las masas, reducen la participación ciudadana activa y apuntalan, en consecuencia, un ordenamiento autocrático sustentado en el miedo a la crisis, independientemente de cuál sea la naturaleza de la crisis.

\section{Metodología}

La investigación se sustentó en el método hermenéutico por ser el que mejor se adapta a diseños documentales en los cuales prevalece el interés por interpretar y dialogar con un conjunto selecto de texto en su contexto multidimensional. Como indican (Arbeláez-Campillo et al, 2018; ArbeláezCampillo, 2019; Arbeláez-Campillo et al., 2020) la hermenéutica implica un tipo de lectura profunda, que no solo se conforma con la exegesis de una obra en particular, decodificando sus mensajes claros u ocultos. Se trata también de una postura epistemológica que asume las realidades textuales y contextuales como una construcción intersubjetiva que refleja la cosmovisión general de una época y cultura determinada, la cual puede ser leída y releída sin llegar a agotar nunca sus verdades intrínsecas.

O modo de técnica para la recolección de información se emplearon las entrevistas abiertas con guion semiestructurado en dos connotados intelectuales latinoamericanos. Por último, se procedió a triangular los postulados de las teorías seleccionadas, la opinión de dos expertos en la materia y la perspectiva particular del equipo de investigación. Por lo demás, el diálogo con los investigadores entrevistados se generó en torno a las siguientes interrogantes: 


\begin{tabular}{|cl|}
\hline \multicolumn{1}{|c|}{ Objetivo general de la investigación: } \\
Debatir distintas lecturas sobre el binomio: miedo y control social \\
en los dominós del derecho, la teoría crítica de la sociedad, el pen- \\
samiento posestructuralista de Michel Foucault y la doctrina del \\
shock.
\end{tabular}

\section{Cuadro No. 2. Guion de preguntas con base al objetivo de la investigación (Elaboración propia).}

Como se puede suponer, el texto que se presente se inscribe en el llamado paradigma cualitativo de investigación científica y surge, igualmente, apropósito de la crisis internacional generada desde principios del 2020 por la pandemia del COVID-2019 que bien podría transformar radicalmente el orden mundial vigente dando paso a un statu quo signado por el miedo y el CS de tipo autoritario. Del mismo modo, el trabajo en cuestión es en buena medida subsidiario de los aportes gnoseológicos de las teorías y enfoques seleccionados y, especialmente, de las ideas y opiniones suministradas por los sujetos entrevistados, más allá de lo polémicas que puedan resultar en algunos tópicos debatidos. 
Panchenko Olha, Danilyan, Oleg G., Viktoriia Lytoyn, Diego Felipe Arbeláez-Campillo, Magda Julissa Rojas-Bahamón, Maryna Halych y Larysa Rybyk

Lecturas del miedo y control social en la teoría sociocrítica y posmoderna

\section{Miedo y control social en la teoría sociocrítica y posmoderna}

De conformidad con la experiencia previa desarrollada por Calvano (2019) en el manejo de entrevistas en profundidad, en este apartado se efectúa una sinopsis de los relatos proporcionados a dos voces por el profesor Reyber Parra Contreras ${ }^{12}$ y el joven filósofo y politólogo Moisés Flores ${ }^{13}$, mediante conversaciones por WhatsApp desarrollas la última semana de mayo de 2020, en razón de la política de cuarentana social implementada como un intento de reducir las posibilidades de contagio del COVID-2019, lo que impidió nuestro contacto cara a cara.

Ante la primera pregunta ganada a indagar la relación que se da, en la teoría y en la realidad, entre las variables: miedo-control social, Parra (2020 a) argumentó que el miedo no es solo una construcción teórica, sino que está presente en las conductas individuales y colectivas de ahí el interés de pensadores como Antonio Gramsci y Michel Foucault, entre otros, por generar teorías que explicaran las implicaciones políticas e ideológicas de este fenómeno que connota CS. Por su parte, Flores (2020), efectuó una reseña histórica para destacar el modo como el CS se ejerció en los gobiernos totalitarios del siglo XX, específicamente por los NAZIS y comunistas de era de Stalin, donde se evidencia una estrategia de deliberada de controlar a las masas mediante la reproducción del miedo, que recuerda -a su modo de ver- la premisa maquiavélica que reza: "Es preferible que te teman a que te amen, porque si te aman pueden hacerte daño, en cambio si te temen no..."

De igual modo, al decir de Flores (2020) lo modelos políticos que se basan fundamentalmente en la inducción social del miedo como garantía de control, erosionan el repertorio de libertades humanas y tienen, efectivamente, pretensión de estructurar un ordenamiento totalitario, esto es, un sistema que no diferencia entre la esfera pública y privada de los mundos de vida y busca controlar por completo la vida de personas y comunidades con base a dogmas e ideologías fundamentalistas que menoscaban la dignidad humana.

Los modelos de "control social duros" funcionan mediante estados policiales que suprimen violentamente todo ápice de libertad individual y librepensamiento (Flores, 2020). Para el filósofo marabino, en el mundo de hoy la cuestión está en determinar hasta qué punto es legítimo un esquema de CS fuerte en democracia para preservar la seguridad colectiva amenazada continuamente por fuerzas antidemocráticas como el terrorismo $\mathrm{u}$ organizaciones radicales, sin que este control termine

12 Profesor titular de la Universidad del Zulia. Historiador, experto en historia del pensamiento político. Email: reyberparra@gmail.com

13 Investigador independiente. Experto en filosofía y teoría política. Email: moisesfr88@gmail.com 
asfixiando las posibilidades de ser y hacer propias de un mundo libre que respeta la voluntad y conciencia de una ciudadanía que valora su privacidad y autonomía. En este caso, el CS se daría en el acceso a información sensible o en la amenaza del uso de la fuerza más que en la coerción pura, como condición para garantizar la propia existencia y autoridad del Estado y su status quo.

Para responder a la segunda interrogante sobre si los sistemas conocidos de control social precisan como condición de posibilidad de los imaginarios del miedo, Parra (2020 a) sostuvo que, a su criterio, todos los sistemas de CS propician, en mayor o menor medida, el miedo para inhibir las conductas que atentan contra el orden establecido que se busca preservar a toda costa. El problema radica cuando solo se usa el miedo como forma de controlar a las masas en detrimento de los incentivos que proporciona la legitimidad por desempeño de un modelo y de una gestión en particular que, se gana el compromiso y aceptación de las personas bajo la premisa que el orden que se tiene beneficia el desarrollo de sus vidas y es, por tanto, más deseable que el caos o la rebelión permanente propia del momento pre-estatal o el llamado estado de naturaleza.

Ante la misma pregunta Flores (2020), argumento que en los sistemas realmente democráticos la necesidad del CS formal es mínima toda vez que existen -al menos en teoría- un conjunto de leyes y protocolos racionales desarrollados consensuadamente entre los órganos del poder público y la sociedad en general, los cuales permiten gestionar la conflictividad social e incluso situaciones catastróficas sin la necesidad de apelar al uso arbitrario del poder, tal como se visualiza, verbigracia, en la figura límite del Estado de excepción que viene a sustituir en el constitucionalismo contemporáneo y más concretamente en los paradigmas jurídicos del Estado social de derecho y de justicia o en el Estado constitucional de derecho, al toque de queda que suspendía el goce y disfrute de las garantías constitucionales básicas.

Sin embargo, Flores (2020) reconoce que en la práctica en ciertas situaciones de catástrofe o calamidad colectiva pueden desbordarse los protocolos que regulan la acción coercitiva de la fuerza del Estado por el factor humano, generando un escenario de crisis y de violencia general que amerite el uso del control social duro como condición de posibilidad para rescatar un umbral mínimo de gobernanza y gobernabilidad, sin el cual no es posible la convivencia. Estas situaciones de estallido social que se dan por causas multidimensionales siguen suscitando acalorados debates entre juristas, filósofos y científicos sociales que oscilan entre posiciones libertarias que defienden la desobediencia civil y el derecho de resistencia a la opresión, hasta perspectivas neoconservadoras que justifican bajo ciertas condiciones la violencia de Estado como recurso indiscutido para la auto-preservación del orden sistémico. 
Panchenko Olha, Danilyan, Oleg G., Viktoriia Lytoyn, Diego Felipe Arbeláez-Campillo, Magda Julissa Rojas-Bahamón, Maryna Halych y Larysa Rybyk

Lecturas del miedo y control social en la teoría sociocrítica y posmoderna

Al formular la tercera interrogante ¿Ciertas coyunturas catastróficas como las pandemias auspician el uso arbitrario del control social a través de la inducción colectiva del miedo? Parra (2020 a) sostiene que las circunstancias catastróficas han servido históricamente para manipular el miedo colectivo e inhibir las conductas que no favorecen al sistema político. Ante las amenazas latentes o reales las personas y grupos que ocupan los principales espacios de poder vinculante se aprovecha de la situación para neutralizar, no solo las llamadas "conductas desviadas" sino hasta prácticas como el pensamiento crítico y la libertad de expresión, realidad mucho más patente en gobiernos poco o nada democráticos que se sirven de la teoría del shock.

Del mismo modo, Flores (2020) supone que hay sociedades mucho más disciplinadas que otras y, en consecuencia, son capaces de autorregularse y responder sin necesidad de la intervención de un locus de control externo de formas eficaz y efectiva a situaciones de emergencia colectiva. Tal es el caso, por ejemplo, de Japón, que ante contextos de tsunamis u otras calamidades naturales no reacciona con saqueos o disturbios. No obstante, existen también formaciones sociales menos cohesionadas como el caso de la sociedad norteamericana en la cual las situaciones de emergencia social demandan del uso arbitrario del CS para reducir el caos. En estos casos, el poder militariza a la sociedad con el pretexto de recuperar el orden obliterado por los focos de violencia social.

A nuestro modo de ver, las situaciones de catástrofe como las pandemias, entre otras, sacan a relucir un conjunto de problemáticas de diverso signo subyacentes en el seno del tejido social, invisibilizadas por la cotidianidad, tales como: la discriminación racial, la subordinación de minorías, la injusticia social, los desequilibrios económicos y las hambrunas, que en el caso del mundo coetáneo, demandan respuestas urgentes (Parra, 2020 b).

La cuarta pregunta indaga sobre si hay razones de peso para suponer que en el momento actual signado por la pandemia COVID-2019, ciertos gobiernos están haciendo un manejo de la crisis similar a la teoría del Shock, a lo cual Parra (2020 a) sostiene que sí, que los gobiernos que no se orientan por un contrato social democrático se valen de la tragedia del COVID-19 para manipular la información y presentarse como "dueños de la verdad de lo que acontece"; en esta ecuación se propaga el miedo al virus y se apuntalan aún más las tecnologías de CS aun punto que recuerda los postulados del biopoder de Foucault, mediante el cual ya no solo se controlan el uso de los espacios públicos sino además el cuerpo humano, delimitando las normas de higiene personal, conductas y hábitos alimenticios mediante las normas de bioseguridad. Aquí el estado vigila la disciplina y castiga a los infractores.

Por su parte, ante la misma pregunta Flores (2020), señala que conviene revisar desde que perspectiva se emplea y entiende a la teoría del shock 
porque se trata de un concepto imaginado por un autor de izquierda para describir originalmente como gobiernos neoliberales se sirven de ciertas crisis para implementar políticas que reducen al estado de bienestar y erosionan los parámetros de seguridad social que adquieren desde la declaración universal de los derechos Humanos de 1948, la categoría de derecho fundamental. Por lo tanto, toca identificar en la investigación social más allá de la reflexión teorética ċcuáles políticas y en qué países? se implementan en el sentido que señala Naomi Klein.

Además, interesa precisar también de qué modo gobiernos de izquierda radical en el mundo, ganados a las economías planificadas se sirven de la teoría del shock sin necesariamente implementar políticas neoliberales. Desde nuestra perspectiva, la opinión de Flores (2020) es mucho más pertinente cuanto que la tendencia internacional en el manejo de la pandemia ha significado un reposicionamiento del estado nacional como principal garante del bienestar colectivo, a contravía de los postulados del estado mínimo y de la iniciativa privada como factores regulares del conflicto social postulado por los fundamentalismos economicistas.

En definitiva, Flores (2020) asegura que el caso de la pandemia del COVID 19 la crisis no tiene necesariamente nada que ver con lo postulado en la teoría del Shock, porque nadie creo deliberadamente la crisis y las políticas neoliberales que promocionan el Fondo Monetario Internacional o el Banco Mundial no se adaptan en nada a los requerimientos sanitarios del momento que demandan maximizar los servicios de salud pública. Argumentar en contrario sería - desde su punto de vista- incurrir en los dominios de la teoría de la conspiración o de simple especulación sin conexión con los hechos.

$\mathrm{Al}$ responder a la última pregunta formulada para determinar cuál sería la estrategia de resistencia más adecuada en el seno de la sociedad civil organizada, para rechazar a las políticas de propagación del miedo como CS y, en este sentido, valorar si tienen algún aporte práctico que hacer los paradigmas sociocrítico y posmoderno seleccionados por los autores de este trabajo, Parra (2020 a) sostiene que la mejor estrategia de resistencia implica el manejo social de información veraz que refleje la realidad.

Esta es la diferencia esencial de las poliarquías con los sistemas autocráticos, donde el manejo de la información basado en la ideología y la propaganda distorsiona más bien la realidad, al tiempo que desinforma a las masas. Parra (2020 a) argumenta asimismo que incluso en contextos de información tendenciosa o de poca calidad las personas pueden desplegar su pensamiento crítico y buscar mejores fuentes de información que apuntalen su conocimiento de la realidad e informen en cada momento su proceso de toma de decisiones. 
En contraste, Flores (2020) señala que, si fuera el caso de que algunos estados nacionales negaran arbitrariamente el goce y disfrute de los derechos humanos con la excusa de manejar la pandemia, entraríamos a un panorama que justifica el despliegue de estrategias de resistencia por parte de la sociedad civil organiza, ahí donde existe una sociedad con conciencia histórica y política dispuesta a resistir. En líneas generales, no existe al menos en las democracias occidentales una política de propagación del miedo como CS, se trata hasta ahora de un evento natural que surge cíclicamente en la historia humana como lo son las pandemias.

Según Flores (2020) son los medios de comunicación social, quizá sin proponérselo, los que socializan el miedo y hasta la paranoia colectiva a la epidemia. Recuerda el caso de Guayaquil donde se vivió un lúgubre fenómeno de quema colectiva de cuerpos en la vía pública por el colapso de los servicios públicos, reseñado sin ninguna discreción por la prensa de mayor divulgación a nivel mundial. Coincide con Parra (2020 a), en que la mejor estrategia de resistencia civil ante la crisis y el uso político de la calamidad consiste en informarse con fuentes fidedignas para hacer una lectura coherente de la realidad local, nacional y mundial. Se trata, tal como señala Albert Camus en su afamada obra La peste de 1947, de resaltar el valor de la solidaridad humana para ayudar a los que más lo necesitan y más sufren ante la enfermedad y su consecuente parálisis económica.

\section{Conclusiones}

- En el proceso de triangulación que vinculó dialécticamente una muestra de la teoría sociocrítica y posmoderna, con el relato de dos destacados científicos sociales no existe, a nuestro modo de ver, mayor disparidad o disonancia de criterios, salvo en sentido que Flores (2020) ve a la teoría del Shock como un constructo poco adecuado para explicar el actual escenario internacional signado por la pandemia del nuevo coronavirus. Se da más bien una relación de complementariedad entre las teorías y opiniones recabadas que converge también con la opinión de los autores de este artículo.

- Desde la perspectiva del equipo de investigación queda claro que el miedo se presenta como un factor inhibidor de la acción colectiva, retardando en muchos casos los necesarios procesos de cambio que rompen con el estancamiento de la tradición e impulsan -bajo ciertas condiciones- el salto cuántico de la humanidad a una fase cualitativamente superior de su existencia o, al menos, propician acciones de resistencia y protesta social. Por lo demás, supera las posibilidades de esta investigación determinar en qué países y contextos se exacerba el natural miedo a la enfermedad con fines de CS. 
- Por las razones descritas conviene alertar, en la labor de investigación científica con independencia de su enfoque, disciplina y método, que la teoría no puede en ningún caso sustituir la evidencia empírica concreta que se debe recabar en la propia realidad, como entidad única y particular en cambio permanente.

- Cuando se intenta debatir distintas lecturas sobre el binomio: miedo y control social en los dominós del derecho, la teoría critica de la sociedad, el pensamiento postestructuralista de Michel Foucault y la doctrina del shock, surgen hallazgos inesperados de orden gnoseológico. Todo indica que el distanciamiento histórico del derecho, en tanto ciencia jurídica, con el patrimonio epistemológico compartido por las ciencias sociales de cara al pensamiento crítico han repercutido en el debilitamiento del primero cuando se trata de entender en profundidad las situaciones de crisis y calamidad colectiva.

- En este sentido, conviene impulsar el desarrollo de un derecho crítico que no solo se ocupe del estudio de la producción normativa que sirve de sostén al orden establecido, sino además de propiciar la transformación ordenada y justa de los modelos políticos, económicos y sociales cuando así lo amerite el movimiento histórico.

- Al parecer la pandemia del COVID 19 tiene el potencial de desarticular de formas inusitadas el orden mundial vigente hasta el momento presente tal como demuestran Arbeláez et al (2019). Consecuentemente, el uso arbitrario del CS dependerá en cada caso del modo como las tendencias democráticas o autocráticas logren determinar el curso y el contenido de los nuevos o renovados modelos políticos y económicos que se edifiquen o mantengan en cada país y sociedad. De cualquier modo, las estrategias de resistencia civil y movilización ciudadana juegan un rol primordial para inclinar la balanza del lado de las democracias y ganar más espacios de poder no regimentado en los escenarios venideros.

- Por último, los autores de la investigación postulan la necesidad de diseñar una teoría interdisciplinaria del CS que parte de los aportes epistemológicas del paradigma jurídico, sociocrítico y posmoderno pero que vaya más allá en su afán compresivo y explicativo, toda vez que los modelos debatidos provienen de realidades muy distintas a la latinoamericana y de una época en la cual las tecnologías de dominación y control no habían avanzado tanto como ahora en el siglo XXI, donde prevalece el uso generalizado de la inteligencia artificial, las nuevas tecnologías de comunicación y la internet. 
Panchenko Olha, Danilyan, Oleg G., Viktoriia Lytuyn, Diego Felipe Arbeláez-Campillo, Magda Julissa Rojas-Bahamón, Maryna Halych y Larysa Rybyk

\section{Referencias Bibliográficas}

ARBELÁEZ-CAMPILLO, Diego Felipe. 2019. "Política eideología en la literatura latinoamericana" En: Cuestiones Políticas. Vol. 35, No. 62, enero-junio, pp. 108-128.

ARBELÁEZ-CAMPILLO, Diego Felipe; ANDREYEVNA DUDAREVA, Marianna; ROJAS-BAHAMÓN, Magda J. 2019. "Las pandemias como factor perturbador del orden geopolítico en el mundo globalizado" En: Cuestiones Politicas. Disponible en línea. En: https://produccioncientificaluz.org/index.php/cuestiones/article/ view/31528/32609. Fecha de consulta: 17/03/2020.

ARBELÁEZ-CAMPILLO, Diego Felipe; ROJAS-BAHAMÓN, Magda J; ARBELÁEZ-ENCARNACIÓN, Tanya Fernanda. 2018. "Apuntes para el debate de las categorías ciudadanía universal, derechos humanos y globalización” En: Cuestiones Politicas. Disponible en línea. En: https://produccioncientificaluz.org/index.php/cuestiones/article/ view/30192/31209. Fecha de consulta: 12/01/2020.

ARBELÁEZ-CAMPILLO, Diego Felipe; VASYL, Tatsiy; ROJAS-BAHAMÓN, Magda J; DANYLAN, Oleg. 2020. "Contributions of Critical Thinking As a Form of Participation and Political Deliberation" En: Amazonia Investiga. Disponible en línea. En: https://doi.org/10.34069/ AI/2020.27.03.1. Fecha de consulta: 12/04/2020.

BENJAMIN, Walter. 2001. Para una crítica de la violencia y otros ensayos Iluminaciones IV. Taurus. Madrid, España.

CALVANO CABEZAS, Leonardo. 2019. "Apuntes sobre los desafíos que entraña el nuevo contrato social para Colombia en tiempos del postconflicto" En Cuestiones Politicas. Disponible en línea. En: https://produccioncientificaluz.org/index.php/cuestiones/article/ view/31521/32603. Fecha de consulta: 12/03/2020.

CANELÓN, Fidel. 2009. Ensayos de modernidad y posmodernidad. Fundación editorial el perro y la rana. Caracas, Venezuela.

CENTRO PARA EL ESTUDIO Y PREVENCIÓN DE LA DELINCUENCIA (CRIMINA). 2014. Término CRIMIPEDIA: Teorías del control social. Disponible en línea. En: http://crimina.es/crimipedia/wp-content/ uploads/2015/07/Teor\%C3\%ADas-del-control-social.pdf. Fecha de consulta: 17/06/2020. 
DAVID, Pedro R. 1979. Estructura social y criminología. Instituto de Criminología Universidad del Zulia. Maracaibo, Venezuela.

FLORES, Moisés. 2020. Miedo y control social 2. (ARBELÁEZ-CAPILLO, Diego, Entrevistador). 14 p.

FOUCAULT, Michel. 1980. Microfísica del poder. Las Ediciones de la Piqueta. Madrid, España.

FOUCAULT, Michel. 2002. Las palabras y las cosas Una arqueología de las ciencias humanas. Siglo veintiuno editores Argentina. Buenos Aires, Argentina.

FOUCAULT, Michel. 2007. Nacimiento de la Biopolítica Curso en el colegio de Francia (1978-1979). Fondo de cultura económica. México DF., México.

FOUCAULT, Michel. 2008. Vigilar y castigar El nacimiento de la prisión. Grupo editorial siglo veintiuno. Buenos Aires, Argentina.

FROMM, Erich. 1994. La patología de la normalidad. Paidós. Barcelona, España.

FROMM, Erich. 2003. Ética y psicoanálisis. Fondo de Cultura Económica. México DF., México.

HABERMAS, Jürgen. 1999. La inclusión del otro Estudios de teoría política. Paidós. Barcelona, España.

HABERMAS, Jürgen. 2000. Facticidad y validez Sobre el derecho y el Estado democrático de derecho en términos de teoría del discurso. Trotta. Barcelona, España.

HORKHEIMER, Max; ADORNO, Theodor. 1998. Dialéctica de la Ilustración Fragmentos filosóficos. Editorial Trotta. Valladolid, España.

HURTADO, Fina Antón. 2015. “Antropología del miedo" En: Methaodos. Revista de Ciencias Sociales. Vol. 3, No. 2, noviembre, pp. 262-275.

LASO, Silvana. 2004. "La importancia de la teoría crítica en las ciencias sociales" En: Espacio Abierto. Vol. 13, No. 3, julio-septiembre, pp. 435-455.

MARCUSE, Herbert. 1993. El Hombre Unidimensional Ensayo sobre la Ideología de la Sociedad Industrial Avanzada. Planeta-Agostini. Barcelona, España.

MÁRQUEZ RAMÍREZ, Jesús Alberto (2020). "Aportes de la Modernidad al desarrollo de la teoría democrática”. En: Revista Latinoamericana de Difusión Científica. Vol. 2, No. 2, enero-junio, pp. 69-92. DOI: https:// doi.org/10.38186/difcie.22.06 
Panchenko Olha, Danilyan, Oleg G., Viktoriia Lytvyn, Diego Felipe Arbeláez-Campillo, Magda Julissa Rojas-Bahamón, Maryna Halych y Larysa Rybyk

MORALES CASTRO, Yolanda Rosa. 2018. Familia y socialización política en Colombia. UNERBM/Universidad del Zulia. Cabimas, Venezuela.

NAOMI, Klein. 2008. La doctrina del shock El auge del capitalismo del desastre. Paidós. Buenos Aires, Argentina.

NUSSBAUM, Martha. 2012. Crear Capacidades Propuesta para el desarrollo humano. Paidós. Barcelona, España.

ORWELL, George. 2008. 1984. Debolsillo. Barcelona, España.

PARRA CONTRERAS, Reyber. 2020 a. Miedo y control social 1. (ARBELÁEZCAPILLO, Diego, Entrevistador). 12 p.

PARRA CONTRERAS, Reyber. 2020 b. "Una perspectiva del mundo que se nos avecina”. En: Revista de la Universidad del Zulia. Vol. 11, No 29, pp. 3-5. DOI: http://dx.doi.org/10.46925/rdluz.29.01

SALAZAR, Robinson. 2009. "La nueva estrategia de control social. Miedo en los medios y terror en los espacios emergentes” En: Quórum Académico. Vol. 6, No. 2, julio-diciembre, pp. 105-123.

VILLASMIL ESPINOZA, Jorge. 2017. "Saberes emergentes, intervención social crítica y nuevo contrato social en la Colombia del siglo XXI" En: Reinventado saberes para la intervención social. MUÑOZ DE RUEDA, Ligia; MORALES CASTRO, Yolanda (editoras). Universidad Simón Bolívar. Barranquilla, Colombia. 


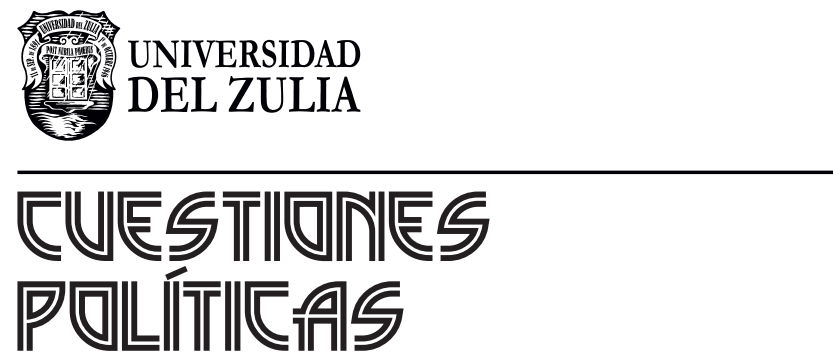

Vol.38 NEspecial

Esta revista fue editada en formato digital y publicada en octubre de 2020, por el Fondo Editorial Serbiluz, Universidad del Zulia. Maracaibo-Venezuela 